\title{
The Effects of Music on Student Step Counts and Time in Activity in College Basketball Activity Classes 音樂效果對大學籃球課學生步數和活動時間的影響
}

\author{
David BARNEY \\ Brigham Young University, U.S.A. \\ Keven PRUSAK \\ Brigham Young University, U.S.A. \\ Lindsey BREWER \\ Brigham Young University, U.S.A.
}

\begin{abstract}
Music is a powerful influence in life. We hear music at work, in the car, at the mall, and in our homes. Music has also been found to have an affect during physical activity. The purpose of this study was to examine the effects of music on physical activity rates, via pedometers, of college-aged students in basketball class. For this study 106 collegeaged students participated in this study. Two classes played basketball with no music playing during game play. Two other classes played basketball with music playing during game play. It was found that the two classes that played basketball with music took more steps and were in more time in activity.
\end{abstract}

Keywords: College Students, Basketball, Music, Physical Activity, Pedometers,

\section{Introduction}

The literature has found music to be a positive tool when used in a physical activity setting. For example, background music has been shown to reduce perceived exertion by $10 \%$ (Nethery, 2000), enhances endurance (Rendi, Szabo, \& Szabo, 2008), and helps 'colour' how a person interprets their perceptions of fatigue (Karageorghis \& Lee-Priest, 2012). With the increased number of studies dealing with the effects music has on physical activity, a conceptual framework has been established to provide support to the research. Karageorghis, Jones, and Low (2006) proposed a conceptual framework of four factors how music in a physical activity setting can affect a person: they are a) rhythm response, b) musicality, c) cultural impact, and d) association. Rhythm response refers to the musical rhythm, most notably tempo, or speed of music as measured in beats per minute. Musicality refers to the response to pitch-related elements, such as harmony and melody. The cultural impact refers to the pervasiveness of the music within society. And association pertains to the extramusical association apiece may evoke. The factors exhibit a hierarchical structure (i.e., rhythm response is the most important contributor to the motivational quotient of a piece of music).

As mentioned previously, a body of research has been established in a variety of context within the physical activity setting. For example, Karageorghis, Jones, and Low (2006) investigated the link between exercise intensity and music tempo and music tempo preference. College-aged students were to pick their top-three artists for use in the study then walk on a treadmill at levels of intensity while wearing a heart rate monitor and listening to the selecting of music. Results indicated, that the college-aged students preferred fasttempo music and the fast-tempo music accompanied increases in workload intensity. In a similar study, Copeland and Frank (1991) compared college-aged students walking on a treadmill, listening to soft/slow 
tempo music and upbeat/fast tempo music. It was found that the students listening to the soft/slow tempo music generally exhibited a lowered heart rate compared to an exercise group that listened to upbeat/fast tempo music.

For much of the research dealing with the effects of music on physical activity, it has been conducted in laboratories or in fitness clubs. Another context music research has taken place in is the physical education setting. Deutsch and Hetland (2012) examined $4^{\text {th }}$ and $5^{\text {th }}$ grade students' scores and impact of music, perceived enjoyment and perceived work effort throughout the PACER (Progressive Aerobic Cardiovascular Endurance Run) test in elementary physical education classes. For this study students experienced one of three variation provided by the PACER CD: version 'A' with a hightempo background music; version ' $\mathrm{B}$ ' with a mild-tempo background music; and a version 'w/o' that included no music. After the completion of the PACER test students filled out a survey regarding the effort they gave, if they enjoyed the music that played during the PACER test, if the music motivated the student during the test, and their rating of their performance. It was found that the student's generally scored higher on the PACER test when one of the two music versions was played during the test. The researchers went on further to suggest that the female students performed better with version 'A' (faster tempo) music. The male student's performed better in the PACER test with the version ' $\mathrm{B}$ ' (mild tempo) music. The results from the survey after the PACER test found students had a better attitude toward the PACER test when music was played.

A second study in a physical education setting investigated the effects of music on physical activity of elementary children during physical lessons (Barney $\&$ Prusak, 2015). For this study $1153^{\text {rd }}, 4^{\text {th }}$ and $5^{\text {th }}$ graders participated in two Frisbee lessons and two walking activities lessons. One lesson for both activities had music and the other lesson had no music playing. It was found that the students were more active in both lessons with music playing. Another finding from this study was that the student's preferred fast-tempo music and when the fast-tempo was playing, the workload intensity increased.
One last study in a physical education setting, investigated the effects of contingent music on laps run in a high school physical education class (Ward \& Dunaway, 1995). For this study the researchers used a high school physical education class of 36 students. The researchers randomly selected four students to observe their running of laps during class. It was found that the number of laps ran increased from one lap to nearly three laps per minute when music was played for the four students. Thus representing an increase in the exercise pattern of half a mile per lesson. These research studies have shown that music can positively affect student output in a physical education class. With the results from these studies in a physical education setting, further research is needed to investigate the effects of music on student physical activity in a physical education setting.

The physical education setting offers students a multitude of curricular offerings for all grades. Of the many curricular offerings, basketball is on of the more popular curriculum units. Because of the nature of the game of basketball, it has plenty to offer to those that participate. The Sport Business Daily (2009) reported that in 2008, 26 million people participated in basketball as a form of physical activity. With these numbers of participants and the amount of physical activity basketball has to offer, this presents an opportunity to investigate music's affect along with basketball. Thus, the purpose of this study was to examine the effects of music on physical activity rates (step counts and time in activity) via pedometers, of college-aged students in basketball class.

\section{Methods}

\section{Participants and Setting}

Participants were 106 college-aged students (102 males and 4 females) from a private university located in the western United States. The university Institutional Review Board (IRB) granted approval to conduct this study. Student consent was also secured. The participants were enrolled in four intermediate basketball classes at a private university in the western United States. The lessons for all four classes consisted of 10 minutes for the students to shoot around, to serve as a warm-up and 30 minutes of game play. 


\section{Pedometer Instrument}

The method of measuring the effects of music on physical activity rates during the basketball classes was with pedometers. Pedometers are practical, easy to use, and very cost effective (Barfield, Rowe, \& Micheal, 2004; Beighle, Pangrazi, \& Vincent, 2001; \& Welk, Corbin, \& Dale, 2000). The pedometers have been found to be reliable and valid instruments to measure activity in the basketball classes (Vincent \& Pangrazi, 2002). For this study the Yamaz Digi-Walker LS 2525 was the pedometer used to collect student step counts and time in activity (LeMasurier, Beighle, Corbin, Darst, Morgan, Pangrazi, Wilde, \& Vincent, 2005).

\section{Music Selection}

The music selection used for this study consisted of popular, upbeat fast tempo (120 to 160 BPM) songs suggested by researchers (Priest, Karageorghis \& Sharp, 2004 \& Karageorghis, Jones \& Low, 2006. This researcher compiled a list of 40 songs, and then the researchers listened to the songs and narrowed them down to songs they felt appropriate to play during game play in the basketball classes. The songs that fit the requirements were made into a playlist, put on a $\mathrm{CD}$ to be played over a loud sound system in the gymnasium.

\section{Procedures and Data Collection}

A convenience sampling of four college activity basketball classes was employed in a quasi-experimental design to collect data for this study. The researchers contacted the instructors for the basketball classes to explain both the study and the method of collecting the data. After each instructor agreed to have their classes participate in the study, the researchers attended the basketball classes and explained the study. All students were assured that their voluntary decision to participate or not participate in the study would not affect their grade in class or class standing. Also, the researchers demonstrated how to successfully wear their pedometer while playing basketball. Students were instructed to reset the pedometers to zero before they began the game play portion of the lesson. On the days of data collection two of the researchers attended class and passed out the pedometers and then at the conclusion of the class, collected the pedometers and student record sheets. On the student record sheet the students would write how many steps they took and how much time they were in activity after they played basketball. Two class periods were allotted to collect data for both classes. Only the researchers had access to the student record sheets. Pedometer data was collected from four separate intact intermediate basketball classes. For the study two classes were randomly selected (one class from each instructor) to play music during game play. The other two classes (one class from each instructor) played basketball with not music during game play. For this study game play was considered full-court games. The lesson format was the same for all lessons, 10 minutes of warm-up, which consisted of shooting around and 30 minutes of game play. It needs to be noted, that the data was collected towards the end of the semester. The reason for collecting data at this stage of the semester was in previous class periods students were participating in drills and activities dealing specifically with basketball. By collecting data at this time of the semester, the researchers could have a better perspective of music's effects on step counts taken and time in activity while playing basketball.

\section{Data Analysis}

Data was analyzed using a one-way ANOVA to assess the effects of having music/no music on pedometer step counts and time in activity during two days of basketball class.

\section{Results}

For this study, a one-way ANOVA was used comparing steps taken and time in activity in two basketball classes that had music playing during game play and two basketball classes that had no music playing during game play. A significant difference in both steps taken and time in activity was found between the classes that played music during game play and the classes that did not play music during game play $(\mathrm{F}(1,94)$ $=22.132, \mathrm{p}<.001),(\mathrm{F}(1,94)=23.007, \mathrm{p}<.001)$ respectively. This analysis revealed that the students in the basketball classes with music playing took more steps (M $=3788, \mathrm{SD}=424.07)$ than the students with no music playing during game play $(\mathrm{M}=3418, \mathrm{SD}=344.00)$. The same applied to time in activity, music played $(\mathrm{M}=$ $30, \mathrm{SD}=3.77)$, no music played $(\mathrm{M}=27, \mathrm{SD}=2.41)$. 


\section{Discussion}

The purpose of this study was to examine the effects of music on physical activity rates (step counts \& time in activity), via pedometers, of college-aged students in basketball classes. The findings indicate that when music is being played during game play in a college physical activity basketball class, students take more steps and are in activity more. Thus the results indicate that when music was playing during game play in the basketball classes the intensity of playing basketball increased. The results from this study concur with previous research dealing with the effects of music on physical activity. These results are similar to what Barney and Prusak (2015), found when they studied the effects of music on elementary-aged students on two different physical education activities (Frisbee and walking activities). When analyzing the results, each lesson consisted of 30 minutes of game play with music playing; they took more steps then the students that were in game play with no music. These results indicate that these students increased their intensity. Karageoghis, Jones, and Low (2006) had similar results with college-aged students when walking on a treadmill at three levels of intensity. The researchers found that fast-tempo music was preferred and when students picked fast tempo music their workload intensity increased. Also, Barney, Gust, and Liguori (2012) studied college students that listened to their MP3 player while they worked out at the campus fitness center. For the study students were surveyed. The college students were asked what type of music they listened to while they worked out, what mode of exercise did they participate in while they worked out, why they listened to an MP3 player when they worked out, and the frequency of the students' work out with music. The college students perceived that the MP3 player helped them to work out more frequently, more intensely, and for longer durations. The results from this study, along with other studies, make a strong case for physical educators to implement music during their lessons for the purpose or increasing physical activity.

\section{Conclusions}

The purpose of this study was to examine the effects of music on physical activity rates (step counts $\&$ time in activity), via pedometers, of college-aged students in basketball classes. The researchers feel that the findings from this study will help increase and strengthen the literature for the betterment of increasing physical activity in a college activity setting, as well as all grade levels. The results of this study appear to coincide with the tenants of Karageorghis et., al. (2006) conceptual theory regarding music and physical activity. The application of this conceptual theory for this study states that music can affect a person's physical activity. The areas that music can affect physical activity are: a) rhythm response, b) musicality, c) cultural impact, and d) association. Because of the type of music (rhythm response) used in this study, most notably the tempo or speed of the music, student's steps and time in activity increased. These results are in agreement with previous research findings that music increases student output during physical activity (Karageoghis, Jones, and Low, 2006; Deutsch \& Hetland, 2012; \& Barney \& Prusak, 2015).

The findings from this study bare the fact that those students during game play with music playing had significantly more steps and more time in activity, then those student that played during game play with no music. Having students in activity for more then half the class period is an objective physical educator's want to achieve (Malina, 1996). Music is a tool that can assist physical educators in meeting the objective of having students in physical activity for a majority of class time. The findings from this study should hint to physical educators of implementing music in game play situations during class. Chen (1985) has said, "Just play some music with a definite beat and watch as little ones respond with the joy of moving in space." Even though Chen is singling out small children the same can apply to any person of any age. Music can move us and, and this can also apply to music being played during game play in college basketball classes.

\section{Study Limitations}

The researchers have noted limitations to this study. Because the participants came from one university, it may not allow a representative sampling of participants from other colleges, universities or geographic regions, thus limiting the generalizability of the findings. Additionally, the research study was conducted at a private university, which may further limit the generalizability of the findings. Thus, the conclusions and implications are mostly applicable to those participant's demographics. 


\section{References}

Barfield, J. P., Rowe, D. A., \& Michael, T. J. (2004). Interinstrument consistency of the yamax digiwalker pedometer in elementary school-aged children. Measurement in Physical Education and Exercise Science, 8, 109-116.

Barney, D., Gust, A., \& Liguori, G. (2012). College students' usage of personal music players (pmp) during exercise. ICHPER*SD Journal of Research, 7, 23-26.

Barney, D., \& Prusak, K. (2015). The effects of music on physical activity rates on elementary physical education students. The Physical Educator, 72, (2), 236-244.

Beighle, A., Pangrazi, R. P., \& Vincent, S. D. (2001). Pedometers, physical activity and accountability. Journal of Physical Education, Recreation and Dance, 72, 16-19, 34.

Chen, P. (1985). Music as a stimulus in teaching motor skills. New Zealand Journal of Health, Physical Education \& Recreation, 18, (3), 19-20.

Copeland, B. L., \& Frank, B. D. (1991). Effects of types and intensities of background music on treadmill endurance. The Journal of Sports Medicine and Physical Fitness, 31,(1), 100-103.

Deutsch, J., \& Hetland, K. (2012). The impact of music on pacer test performance, enjoyment and workload. Asian Journal of Physical Education \& Recreation, $18,(1), 6-14$.

Malina, R. M. (1996). Tracking of physical activity and physical fitness across the lifespan. Research Quarterly for Exercise and Sport, 67, (3), 48-57.

Nethery, V. M. (2002). Competition between internal and external sources of information during exercise: Influence of rpe and the impact of the exercise load. Journal of Sports Medicine and Physical Fitness, 42, 172-178.
Priest, D. L., Karageorghis, C. I., \& Sharp, N. C. C. (2004). The characteristics and effects of motivational music in exercise settings: The possible influence of gender, age, frequency of attendance, and time of attendance. The Journal of Sports Medicine and Physical Fitness, 44, 77-86.

Rendi, M., Szabo, A., \& Szabo, T. (2008). Performance enhancement with music in rowing sprint. The Sport Psychology, 75, 175-182.

Karageorghis, C. I., Jones, L., \& Low, D. C. (2006). Relationship between exercise heart rate and music tempo preference. Research Quarterly for Exercise and Sport, 77, 240-250.

Karageorghis, C. I., \& Lee-Priest, D. (2012). Music in the exercise domain: A review and synthesis (Part 1). International Review of Sport and Exercise Psychology, 5, (1), 44-66.

LeMasurier, G. C., Beighle, A., Corbin, C. B., Darst, P. W., Morgan, C., Pangrazi, R. P., Wilde, B., \& Vincent, S. D. (2005). Pedometer-determined physical activity levels of youth. Journal of Physical Activity and Health, 2, 159-168.

Sports Business Daily. http://www.sportsbusinessdaily.com/ Daily/Issues/2009/08/Issue- 220/The-Back-Of-The-Book/ Team-Sports-Participation-Basketball-Remains-TopBaseball-Down.aspx. Accessed December 30, 2013.

Vincent, S. D., \& Pangrazi, R. P. (2002). Does reactivity exist in children when measuring activity levels with pedometers. Pediatric Exercise Science, 14, (1), 5663.

Ward, P., \& Dunaway, S. (1995). Effects of contingent music on laps run in a high school physical education class. The Physical Educator, 52, (1), 2-7. 


\section{Correspondence:}

David Barney, Ed.D.

Brigham Young University

249G Smith Fieldhouse

Provo, Utah 84602

(801) 422-6477

(801) 422-0930 FAX

David_Barney@byu.edu
Keven Prusak, Ph.D.

Brigham Young University

249H Smith Fieldhouse

Provo, Utah 84602

(801) 422-1560

Keven_Prusak@byu.edu

Lindsey Brewer, M.A.

Dixie State University

St. George, Utah 84770

(435) 817-2334

Linz9789@hotmail.com

Table 1. Means, Standard Deviations and Effect Sizes.

\begin{tabular}{|l|c|c|c|c|c|}
\hline & \multicolumn{5}{|c|}{ Group } \\
\hline & \multicolumn{2}{|c|}{ No Music } & \multicolumn{2}{c|}{ Music } & $S D$ \\
\hline Steps & $M$ & $S D$ & $M$ & 424.07 & 0.96 \\
\hline Time in Activity & 3428 & 344.00 & 3788 & & 0.98 \\
\hline
\end{tabular}

Note: $*=\mathrm{p}<.05, * *=<.01, * * *=\mathrm{p}<.001, \mathrm{ES}=$ Cohen's $\mathrm{d}\left(\mathrm{M}_{1^{-}} \mathrm{M}_{2}\right) / \mathrm{SD}$ pooled;

$£ .2=$ small, $\geq .41=$ medium, $\geq .7=$ large 